\title{
Território, educação e língua: notas sobre a afirmação étnica Munduruku no Baixo Tapajós
}

\section{Territory, education and language: notes on the Munduruku ethnicity, Low Tapajós river}

\author{
José Maurício Arrut 1 \\ Judith Costa Vieira ${ }^{2}$ \\ Sâmela Ramos da Silva ${ }^{3}$
}

\begin{abstract}
Resumo: Este texto se constitui em um exercício preliminar de aproximação entre duas temáticas tão interligadas nos contextos de luta por reconhecimento indígena e ainda um pouco distanciadas no contexto de produção analítica. Tratase da tentativa de articular o estudo da retomada das línguas indígenas nos processos de luta territorial, mas especificamente, da intenção de compreender qual o papel que a demanda e implantação de ações de resgate de línguas indígenas desempenham para os sujeitos em processo de emergência étnica e demanda de reconhecimento dos territórios. Essas discussões foram elaboradas com base em entrevistas, observações em campo e análise documental realizadas em diferentes contextos com os dois grupos, os munduruku de Taquara e os munduruku do Planalto santareno.
\end{abstract}

Palavras-chave: munduruku, emergência, língua, território.

\begin{abstract}
This text consist of in a preliminary exercise aproach between two topics of discussion so interconected in the contexts of fight for indigenous recognition and still a little far from the field of analitic production. It takes care of oneself in a trial to link the study of the retaken of the indigenous language in the procedures of territorial fight, more especify, the purpose to comprehend what is the role that the demand and establishment of rescue actions of the indigenous languages perform for the individuals in process of ethnic emergency and the demand of territories recognition. These discussions were elaborated in basis of interviews, field researchs and documental analysis accomplisheds in differents contexts with the two groups: the munduruku of Taquara and the munduruku of Plateau in the city of Santarém-Pará.
\end{abstract}

Keywords: munduruku, emergency, language, territory.

Este é um experimento analítico preliminar, no qual pesquisas independentes são aproximadas para revelar aspectos convergentes de dois processos de afirmação étnica

\footnotetext{
${ }^{1}$ Historiador. Mestre e doutor em Antropologia Social pelo Museu Nacional da Universidade Federal do Rio de Janeiro (UFRJ). Professor do Departamento de Antropologia Social Universidade Estadual de Campinas (UNICAMP).

${ }^{2}$ Advogada, professora do programa de Ciências Jurídicas da Universidade Federal do Oeste do Pará (UFOPA) Mestre em Direito Ambiental pela Universidade do Estado do Amazonas (UEA) e Doutoranda em Ciências Sociais pela Universidade Estadual de Campinas (UNICAMP).

${ }^{3}$ Professora no Curso de Letras Libras na Universidade Federal do Amapá (UNIFAP), mestre em Linguística pela Universidade Federal de Goiás e doutoranda em Linguística pela Universidade Estadual de Campinas (UNICAMP).
} 
do povo munduruku, no Baixo Tapajós, Oeste do estado do Pará. Nossa análise aproximará as situações dos munduruku de Taquara, município de Belterra, e do Planalto, município de Santarém, tendo por ponto de convergência o modo pelo qual a luta pelo território se traduz e se desdobra em luta cultural, tendo na escola um palco privilegiado dessas conversões. Neste contexto, a escola serve de espaço para as elaborações e embates em torno do "resgate" tanto da língua, tornada símbolo cultural da afirmação étnica na região, quanto da terra e de certas concepções de territorialidade. Assim, investigaremos como as duas situações de afirmação étnica munduruku estabelecem, a partir de dinâmicas locais particulares e autônomas, o caminho que liga território, escola e língua.

\section{Quadro geral}

Belterra e Santarém são municípios contíguos e formavam uma mesma unidade administrativa até 1995, quando o primeiro se emancipou do segundo. A comunidade indígena munduruku Taquara está localizada no interior da Floresta Nacional do Tapajós, a cerca de $90 \mathrm{~km}$ da sede do município de Belterra, na margem direita do rio, e atualmente é formada por 32 famílias, que somam cerca de 180 pessoas reunidas em uma só aldeia, de mesmo nome. A Terra Indígena Munduruku-Taquara, que conta com portaria declaratória de 2016, ocupa uma área de 25.323 hectares (SILVA, 2013).

O povo indígena munduruku do Planalto, formado pelas aldeias de Açaizal, Amparador, São Francisco da Cavada e Ipaupixuna, localiza-se a $40 \mathrm{~km}$ da sede do município de Santarém e sua população é estimada pela Secretaria Municipal de Saúde em 607 pessoas. As áreas ocupadas pelos munduruku do Planalto abrangem áreas de várzea e de terra firme, no entorno do lago do Maicá. A área reivindicada pelos indígenas - cujos limites ainda não foram definidos por estudos oficiais - é de, aproximadamente, 12.200 hectares, mas a definição dos limites depende de acordos e negociações - em andamento - entre a comunidade indígena e as comunidades quilombolas do entorno, dada a existência de sobreposições de usos e de interesses.

Esta região, onde o rio Tapajós deságua no Amazonas, é o contexto de grande mobilização étnica recente, contando atualmente com 13 povos indígenas, distribuídos 
por 67 aldeias ${ }^{4}$ e 18 territórios situados em diferentes etapas do processo de reconhecimento, mas sem que nenhum deles ainda tenha sido oficialmente demarcado. Todos os povos indígenas do Baixo Tapajós protagonizaram, portanto, o que a Antropologia chama de processos de etnogênese, ao se articularem como coletividades políticas marcadas por uma adscrição étnica, com base na qual desencadeiam processos de recuperação de memórias, tradições e determinados itens culturais, eleitos como signos privilegiados de contraste étnico-cultural, como é o caso da língua, que assim assume uma função de alteridade, delimitando fronteiras.

Para Bartolomé (2006), o termo etnogênese remete aos processos de emergência social e política de grupos tradicionalmente submetidos à relações de dominação que, a partir de determinado momento, iniciam um "processo de construção de uma identificação compartilhada, com base em uma tradição cultural preexistente ou construída que possa sustentar a ação coletiva". (BARTOLOMÉ, 2006: 43). Tal definição descreve de forma justa o processo de emergência étnica no Baixo Tapajós. A afirmação da identidade munduruku é um caso de insurgência contra uma dominação política e cultural a que estão submetidas essas populações desde o tempo da colonização e que, nas duas últimas décadas, ganhou uma nova dimensão, com as investidas do agronegócio sobre a terra e os recursos da região, ameaçando provocar a dissolução dos seus modos de vida locais e territórios tradicionais.

Apesar de as lutas materiais envolvidas na assunção de uma identidade étnica serem mais evidentes ao analista externo, elas são indissociáveis da dimensão moral envolvida na afirmação étnica e reorganização política dos grupos étnicos. O que chamamos etnogênese é pensado e sentido por estas populações não como uma estratégia de ganhos materiais, mas como uma luta contra o desrespeito que os projetos de desenvolvimento representam às suas formas de vida e concepções de mundo, de forma que a luta pelo território é a expressão material da luta pelo reconhecimento dos seus modos de ser, seus projetos de vida e sua existência enquanto sujeitos morais.

O compartilhamento das ameaças e desrespeitos está na base do processo de

\footnotetext{
${ }^{4}$ Este número é o divulgado pelo Conselho Indígena Tapajós-Arapiuns (CITA), organização que representa os indígenas do Baixo Tapajós. Contudo, este é um número em crescimento considerando que a cada ano novos indígenas se reconhecem na região. Algumas organizações de apoio aos indígenas, como por exemplo, o GCl (Grupo Consciência Indígena) apontam o número de 70 aldeias
} 
construção de uma mobilização e de uma linguagem para a ação política (HONNETH, 2003), inclusive as de caráter étnico. Mas o próprio compartilhamento não é suficiente para explicar os caminhos que tais grupos percorrem na criação de suas novas identidades sociais. No processo de construção de uma identidade coletiva voltada ao reconhecimento moral de uma coletividade há também o processo a reelaboração material e discursiva dos elementos que possibilitam identificar uma unidade substantiva entre tais sujeitos, tanto quanto uma distância com relação àqueles contra os quais se mobilizam. Da mesma forma, tais reelaborações precisam incidir e serem legítimas no espaço público, o que muitas vezes coloca tais grupos diante da necessidade de escolher (e se adequar) a um dos rótulos sociais e legais disponíveis.

A literatura sobre etnicidade no Brasil (ARRUTI, 2014), tem buscado descrever tais processos (designados como etnogênesis ou emergências étnicas) por meio de investigações que não se restrinjam nem à disputa por recursos, nem à descrição pura e simples dos elementos culturais que marcam a distinção substantiva entre os grupos, mas integrando tais dimensões por meio da observação dos processos de mediação política e cultural em que tais grupos estão envolvidos e que estão na base da reelaboração de suas imagens de si e da distância que os separa de outros. Nesta mesma linha, nós optamos pelo uso da expressão "afirmação étnica", por enfatizar a agência desses grupos, entendendo-a como um processo complexo, que se desdobra em diferentes planos ou dimensões, como a nominação, o reconhecimento, a identificação e a territorialização. (ARRUTI, 2006)

Nossa abordagem está baseada na releitura de materiais de campo de pesquisas anteriores 5 realizadas com os indígenas, seus apoiadores e responsáveis públicos pela implantação da educação escolar diferenciada nas escolas indígenas. Nas duas situações selecionadas, o espaço da escola tem concentrado as ações de reorganização

\footnotetext{
${ }^{5} \mathrm{~A}$ pesquisa com os munduruku do Planalto vem sendo desenvolvida por Vieira desde o ano de 2010, com foco nos processos de reconhecimento e luta pela demarcação territorial. Inicialmente tais pesquisas foram destinadas à elaboração de materiais colaborativos (cf. bibliografia), sendo desdobradas atualmente em uma pesquisa de doutorado (PPGCS-UNICAMP) sobre a relação entre direitos locais e direito nacional. A pesquisa com os munduruku da Taquara começou a ser desenvolvida por Silva como militante do Grupo de Consciência Indígena (GCl) e, a partir de 2011, também como estudante de linguística, tendo por foco a relação entre afirmação étnica e a recuperação da língua munduruku, do que resultou sua dissertação de mestrado (Silva, 2013) e seu atual projeto de doutorado (IEL-UNICAMP) sobre a recuperação da língua nheengatu na região.
} 
cultural, muitas vezes pensadas em termos do "resgate" de saberes e falares indígenas, tanto quanto de modos de gestão do território, centrais à luta por reconhecimento na região. Apesar da língua indígena não ter sido fundamental no processo de articulação inicial de suas afirmações étnicas, posto que ambos os grupos não contavam com falantes de munduruku em suas aldeias, em ambos os casos ela acabou se tornando uma das mais importantes demandas desses grupos.

Na primeira parte do texto serão apresentados, em seus traços mais gerais, os processos de emergência étnica dos indígenas munduruku de Taquara e do Planalto, para em seguida abordarmos a dimensão cultural desta luta por reconhecimento, expressa na busca por uma educação diferenciada e, neste contexto, pelo investimento na recuperação da língua munduruku. Por fim, apresentaremos algumas reflexões sobre a relação entre a luta por território e a ideia de "resgate cultural".

\section{A mobilização política munduruku em Taquara e no Planalto}

Os nomes dos povos Tapajó, Arapium, Tupinambá, Borari e Maytapú, entre muitos outros, estão nos registros de viajantes e exploradores que percorreram os rios Tapajós, Arapiuns e Maicá, o Lago Grande da Franca e a imensa região de várzea por eles formada. A grande maioria desses povos foi dizimada nos primeiros anos do contato, vítima de epidemias, guerras e escravidão. No registro que fizeram de sua viagem pela região, entre 1817 e 1820, Spix e Martius registraram apenas a existência de índios vivendo em Santarém como empregados dos colonos ou donos de pequenas roças. Segundo aqueles autores, tal população já seria o cruzamento de numerosas tribos assimiladas, e "muito poucos se recordavam ainda da sua primitiva fala", preferindo usar a "língua geral” (Spix e Martius, 1981, p.100). Em meados do século XIX, a historiografia oficial já declarava extintos os povos indígenas do baixo rio Tapajós (IORIS, 2014), vaticínio que foi sistematicamente repetido nos livros didáticos usados nas escolas da região e do país, do ensino fundamental ao universitário, nos quais os indígenas passam a ser representados como habitantes de um longínquo passado (FONSECA, 2015; SANTOS, 1974).

Isso começou a mudar a partir de 1997, com a criação do Grupo de Consciência Indígena (GCI), por iniciativa de um grupo de jovens militantes universitários e professo- 
res, descendentes diretos de povos indígenas, que tinham na memória as lembranças do que Ihes contavam seus avós. Os militantes do $\mathrm{GCl}$, em sua maioria ligados aos movimentos progressistas da Igreja Católica e oriundos de comunidades rurais, passaram a realizar estudos sobre a história e as tradições culturais dos negros e indígenas no Brasil, particularmente na Amazônia, com o objetivo de "resgatar" e valorizar a história, a identidade e a cultura dos indígenas. Isso está na base dos processos de afirmação étnica na região. Por meio da afirmação da sua identidade indígena, os conflitos que aqueles grupos já travavam com os órgãos governamentais responsáveis pela criação das Unidades de Conservação na região, em especial IBAMA (Instituto Brasileiro de Meio Ambiente e dos Recursos Naturais Renováveis) e ICMBio (Instituto Chico Mendes de Conservação da Biodiversidade), ganham novos sentidos e dinâmicas. O deslocamento compulsório daquelas populações tradicionais, que faz parte dos procedimentos de criação e gestão de determinadas categorias de Unidades de Conservação sob responsabilidade daqueles órgãos, passa a ter por obstáculo, então, a legislação que protege os povos indígenas. A seguir apresentaremos resumidamente como tal dinâmica se deu em cada uma das situações que abordamos aqui.

"Nós não estamos virando índio, nós sempre fomos, mas estavam adormecidos" (Antônio Nazário, comunidade de Taquara)

No caso da comunidade de Taquara, os conflitos materiais que estavam na base de tal mobilização eram decorrentes da implantação da Floresta Nacional (Flona) do Tapajós (loris, 2005 e 2014). Criada em 1974, com uma área de 600 mil hectares, a Flona tem como limites a margem direita do rio Tapajós, a rodovia Santarém-Cuiabá e o rio Cupari, abarcando as comunidades que hoje se organizam em duas Terras Indígenas: Munduruku-Taquara e Bragança-Marituba. Inicialmente, as comunidades da margem direita (Taquara, Bragança e Marituba) e esquerda do rio Tapajós se articularam politicamente com base no Sindicato dos Trabalhadores Rurais de Santarém e foi por meio das suas delegacias sindicais que elas impuseram a primeira resistência à expropriação territorial pretendida pelos órgãos ambientais, em uma época em que a legislação das Florestas Nacionais não permitia a permanência de nenhum residente no interior das reservas (loris, 2014). Mais tarde, porém, tal mobilização de comunidades se desdobraria na articulação com o movimento indígena da região, na medida em que a luta política 
pelo território tradicional daria origem à elaboração de uma memória sobre a posse deste território.

Em 1998, mesmo ano em que a comunidade de Taquara negociava o deslocamento forçado das suas terras, imposto pelos órgãos ambientais, faleceu Laurelino Cruz, seu maior líder espiritual e curador ${ }^{6}$ muito respeitado em toda a região, que se autodeclarava indígena numa época em que todos rejeitavam o rótulo. Originário do alto rio Arapiuns, afluente da margem esquerda do Tapajós, Laurelino se identificava como pertencente à etnia Cumaruara e atendia pessoas que vinham de várias partes da região para buscar sua assistência. Sua morte gerou grande comoção entre os moradores e serviu como uma poderosa contrapartida local à afirmação étnica que já vinha sendo promovido pelo GCl. Abalados pela perda do seu líder espiritual, os moradores de Taquara iniciaram o processo de se assumir como indígenas, como fazia o falecido ancião (VAZ FILHO, 2010; 2011a; 2011b):

\begin{abstract}
Quase todas as atividades sócio-religiosas e políticas da aldeia giram ao redor da memória do Pajé, pessoa muito respeitada na aldeia, não só porque curava as enfermidades com seus poderes espirituais que recebeu do povo munduruku, Tupinambarana e Cumaruara, senão também por seu diálogo permanente com as famílias da aldeia e das comunidades vizinhas e distantes. (LEMOINE, 2005 p. 258)
\end{abstract}

No mesmo ano da morte de Laurelino, os líderes da comunidade procuraram a Funai para informar que eram índios e que estavam reivindicando a demarcação do seu território. O processo de afirmação étnica de Taquara, que passou a receber apoio do $\mathrm{GCl}$, surpreendeu e impactou toda a região, passando a influenciar na vida de muitas outras comunidades ribeirinhas, que possuíam histórias e culturas semelhantes. Entre os munduruku houve a apropriação de pinturas corporais que não eram comuns entre eles, a ressignificação dos rituais, antes praticados somente pelo pajé, os quais passaram a se dar de maneira coletiva, com a defumação do ambiente e com banhos de cheiro, bem como a saudação aos espíritos da natureza, "reapropriada pelos indígenas e transformada em um poderoso sinal diacrítico de indianidade”. (Vaz, 2011 p. 189), que conformam um intenso processo reelaboração cultural.

\footnotetext{
${ }^{6} \mathrm{O}$ nome pajé era evitado (também pelos próprios curadores), provavelmente pelo sentido depreciativo que o termo ganhava na região, ao ser associado ao mundo indígena. Com a afirmação e valorização das identidades indígenas, entretanto, a situação se inverteu e a palavra pajé passou a ser privilegiada para se referir aos curadores. Atualmente, é comum a população local se referir à memória do "pajé Laurelino".
} 
Nos primeiros anos, as comunidades vizinhas e, em especial, indivíduos e grupos com interesses econômicos na área da aldeia, buscaram deslegitimar este processo de afirmação étnica, argumentando basicamente que tal afirmação seria derivada exclusivamente do interesse material nos benefícios a que a legislação indígena daria acesso. Em resposta a estas contestações, o cacique Francisco de Assis argumentou:

Alguém pode até dizer -Ah, vocês querem ser índios só para ganhar a terra. Não é isso. Não queremos ser índio pra ganhar terra. Queremos ser índios prá voltar à nossa cultura, prá buscar nossos costumes e pra retornar à nossa língua, que há quinhentos anos fomos roubados. Prá nós, ser índio resta resgatar tudinho aquela cultura, costumes, aquele bom viver que você tinha com seu irmão, seu parente (...). Semana passada eu estava em Santarém, e uma pessoa me disse: -Ah, lá vocês já querem ser índio. Sempre fomos índios (VAZ FILHO, 2010, p.250).

A postura crítica do pajé Laurelino, que valorizava e positivava suas origens indígenas, só foi compartilhada coletivamente depois de sua morte, quando foi reforçada e teve seu sentido local ampliado simultaneamente pelo trabalho cultural do $\mathrm{GCl}$ e pelo trabalho de memória provocado pelo confronto territorial com os órgãos ambientais. $\mathrm{Na}$ fala do ancião Antônio Nazário, por exemplo, fica claro como a afirmação étnica está estreitamente associada ao "trabalho da memória", na medida em que é por meio da recuperação das narrativas de seu pai, que ele afirma ter descoberto "a nossa origem":

Questão de nós assumir, nós tivemos que procurar...saber de onde nós éramos, da onde nós viemos, a origem. Foi assim que nós descobrimos quem nós somos. Foi aí que nós descobrimos a nossa origem. Aí, agora que tipo de povo? Aí descobrimos, uns...a minha mãe era Arapium, meu tio era Cumaruara, meu pai da etnia munduruku?, desses povo que está aqui. E assim foi que nós descobrimos. Agora, pra sê legalizado mais um pouco, pra gente saber mesmo, tivemos que partir a Funai Itaituba.

Em 2003, a comunidade Taquara recebeu um grupo de trabalho da Funai responsável pelo estudo de identificação e delimitação da terra indígena; em 2009 o seu Relatório Circunstanciado de Identificação e Delimitação foi publicado; mas só em 2016 a Terra Indígena Munduruku-Taquara foi oficialmente declarada.

Já afirmação étnica dos munduruku do Planalto tem seu ponto de partida na observação e na fricção com o processo de afirmação quilombola da comunidades vizinhas, parentes e parceiras. Tais comunidades mantém fortes vínculos familiares, de compadrio, de troca de trabalho e participação nas atividades festivas, assim como acessam conjuntamente recursos naturais, como a coleta do açaí, a pesca e a caça. A reciproci- 
dade é um dado importante na articulação dessas comunidades: a participação de um time no campeonato de outra comunidade, por exemplo, gera para a comunidade receptora a obrigação de "pagar visita". Mas o processo de reconhecimento étnico quilombola e sua vinculação à delimitação de um território, concebido em um modelo legal marcado por fronteiras pensadas como linhas geométricas que separam claramente um dentro e um fora dependentes do pertencimento étnico, altera esta dinâmica de reciprocidade e compartilhamento negociado dos espaços de uso comum.

Em meados dos anos 2000, o processo de organização de comunidades quilombolas atinge o Maicá e a comunidade de Tiningu se articula ao movimento regional, iniciando o processo de delimitação do seu território. Os limites entre as comunidades nunca foi objeto de conflito justamente em função dos dispositivos de reciprocidade a que fizemos referência acima, mas no momento em que o INCRA (Instituto Nacional de Colonização e Reforma Agrária) entra em cena para traçar a linha seca que deveria achar caminho no espaço físico, os problemas surgem. É justamente neste momento que as lideranças da comunidade não-quilombola do Açaizal começam a articular a sua primeira associação, para também fazerem valer seus direitos. A primeira forma de associação foi como moradores, mas depois, respondendo à dinâmica de recuperação de memórias e de investigação sobre a "origem", provocada pela linguagem étnica estabelecida no campo de articulação regional, a comunidade se identifica como indígena. Os moradores de Açaizal começam, então, a participar, com apoio do Conselho Indígena Missionário (CIMI), de oficinas sobre saberes indígenas, sobre remédios caseiros, artesanato, que se transformam em momentos importantes de valorização dos saberes locais, nos quais são explorados também elementos de memória territorial historicamente mais profundos, como é o caso das Terras Pretas e da coleta de material arqueológico que documentaria o caráter indígena do território.

A mobilização no Açaizal também se expressa na esfera pública. A exemplo do que aconteceu com os quilombolas, a prefeitura de Santarém cria, em 2006, a Coordenação de Educação escolar indígena no âmbito da Secretaria Municipal de Educação, com o intuito de implantar escolas indígenas nas aldeias e de começar o processo de discussão de um projeto de educação diferenciada. A escola Dom Pedro II, localizada no Açaizal é, então, enquadrada como escola indígena e desmembrada da escola-sede 
do Tiningu, recentemente reconhecida como quilombola. Isso representa um ganho significativo não apenas do ponto de vista simbólico, na medida em que, a partir de então, a escola do Açaizal passa a comportar mais séries e implanta o ensino de jovens e adultos. As notícias sobre o que vinha ocorrendo no Açaizal se espalham para outras comunidades do entorno e os ganhos recentes da comunidade transformam Açaizal em uma referência para outras comunidades que também não se reconheciam como quilombolas. Tais comunidades vinham sofrendo (e continuam) uma série de restrições, provocadas tanto pelo aumento das cercas que restringem o acesso dos indígenas às áreas apossadas por fazendeiros, quanto pela precarização das relações de trabalho, que passam a compor um quadro de opressão e privação que está na base de sua mobilização por direitos.

Entre os anos de 2010 e 2012 as outras comunidades do entorno do Açaizal, Ipaupixuna, São Francisco da Cavada e Amparador integram a luta e passa a demandar a demarcação de um único território indígena. Formam o Conselho Indígena do Planalto para representar esta demanda conjunta. A partir de então tem encaminhado além dos pleitos territoriais, uma série de denúncias aos órgãos ambientais e participado ativamente dos espaços de discussão da causa indígena tanto regional quanto nacionalmente.

O território indígena munduruku do Planalto não foi ainda reconhecido oficialmente pela FUNAI (Fundação Nacional do Índio), apesar das inúmeras solicitações feitas pelos indígenas. Em maio deste ano o Ministério Público Federal ingressou com uma Ação Civil Pública ${ }^{7}$ perante a justiça federal exigindo a constituição do Grupo Técnico para realização do relatório circunstanciado de identificação e delimitação do território indígena, primeiro passo do processo oficial de demarcação de Terra Indígena no Brasil. O argumento central do órgão ministerial para ingressar com referida ação é a grande vulnerabilidade social em que os indígenas se encontram em decorrência das sérias ameaças de expropriação e danos à saúde e bem estar daquela população, produzidas pelo avanço extensivo da monocultura de soja. Este avanço é favorecido pela falta de controle do Estado sobre o estoque de terras desta região, fazendo com que todo o território ocupado pelos indígenas esteja em disputa.

\footnotetext{
rém.

${ }^{7}$ Processo número 1000141-38.2018.4.01.39.02 tramitando na Justiça Federal da comarca de Santa-
} 


\section{A educação e a língua na luta pelo reconhecimento indígena}

A necessidade de dialogar com os quadros estatais fez com que a mobilização dos grupos indígenas ganhasse formalidade, reproduzindo em parte a língua e a organização estatal, na medida necessária para realizar o trabalho de representação das suas demandas e interesses. Foram formadas, então, as associações indígenas e, conectada a elas, foi se formando uma rede de organizações da sociedade civil que thes serviram de assessoras e mediadoras na compreensão das possibilidades e limitações legais e políticas a que o reconhecimento oficial lhes dava acesso, ao mesmo tempo em que desempenharam as funções fundamentais de divulgar e argumentar, na esfera pública, em favor da "luta indígena" regional.

Do outro lado, quanto mais a questão indígena era posta em destaque, mais os interesses contrários à articulação dessas populações e ao reconhecimento dos seus direitos também buscavam um caminho para frear seus modestos ganhos, seja interferindo diretamente sobre as decisões dos órgãos estatais, seja incidindo e tentando tirar partido das divergências internas a essas comunidades, ou simplesmente negando e disseminando a dúvida sobre a legitimidade de suas identidades. As formas mais comuns desses questionamentos são a negação da "origem indígena" e a exploração do imaginário popular sobre o que seria um povo indígena, para reclamar a ausência nessas comunidades dos sinais diacríticos que supostamente deveriam portar. As acusações de serem "falsos índios" repercutia sobre os próprios grupos, impulsionando-os tanto a mobilizarem contra-argumentos capazes de denunciar o preconceito e os interesses escondidos por trás deles, quanto paradoxalmente, a promoverem ações de "resgate" de cultura e tradições, por meio das quais eles buscam se adequar ao modelo ideologicamente dominante.

No primeiro caso estão, principalmente, os trabalhos de reconstrução de uma memória da ocupação ancestral dos seus territórios e do caráter indígena dessas ocupações, por meio da releitura positiva de uma série de características que eram denegadas até há pouco tempo. Assim, a sobreposição histórica dessas comunidades em relação às "terras pretas", os ancestrais reconhecidamente indígenas, os modos próprios de plantar, extrair, caçar e produzir, profundamente integrados ao ambiente e aproximados aos hábitos genericamente reconhecidos como indígenas, assim como a presença no 
seu vocabulário cotidiano de palavras e expressões com origem em línguas indígenas passam por um processo de ressignificação, deixando de apontar para a "mistura", para apontarem para a "origem". Ainda que todos esses elementos já estivessem presentes na vida dessas pessoas, o que muda é o modo pelo qual são lidos: o que era negativado como característica de uma população cabocla, passa a ser positivado como indicativo de uma origem indígena. Consequentemente, o que era evitado, passa a ser buscado, gerando o paradoxo aparente de uma atitude que ao mesmo tempo que nega as representações estereotipadas sobre os indígenas, baseada em repertórios de traços culturais fixos, também busca "resgatar" tais traços.

No caso do grupo que se identifica como indígenas munduruku do Planalto e de Taquara, vários símbolos da cultura indígena foram introduzidos nos discursos e na prática política desses sujeitos com o intuito de demarcar quem são e o que querem, bem como estabelecer a necessária distinção dos grupos e sujeitos que não se reconhecem como indígenas e que, portanto, têm outros interesses e discursos sobre aquele território em disputa. Se, do ponto de vista teórico e enquanto grupos étnicos, tais coletivos são formas organizacionais vazias, cujo conteúdo cultural (repertório de hábitos e características visíveis) só têm importância analítica enquanto delimitador de uma fronteira com relação a outros grupos, do ponto de vista dos próprios atores, é preciso atribuir substância cultural, biológica e histórica a tais coletivos. Ou seja, mesmo que a formação dos grupos étnicos seja produzida por relações de poder e não pelas diferenças culturais previamente existentes, a cultura é o substrato sobre o qual a diferença se manifesta. $O$ fato da cultura (na verdade da diferença cultural) ser agenciada pelos grupos e estar sujeita a constante variação e recriação (Barth, 2005), implica tanto que ela seja de importância secundária para a teoria sobre os grupos étnicos, quanto de importância primária para a ação social e para as dinâmicas locais.

A organização étnica no Baixo Tapajós apoia-se em um amplo repertório de elementos culturais facilmente identificados como pertencente à cultura indígena regional, tanto quanto se recria constantemente, adicionando aos elementos já existentes outros apreendidos das novas redes sociais em que se inserem, como forma de reforçar e garantir a fronteira relativa aos não indígenas locais. Alguns desses elementos são aprendidos e erigidos como verdadeiras barricadas de defesas contra a negação da identidade, 
e este é justamente o caso da língua indígena.

A seguir delinearemos parte dos esforços realizados por estes dois grupos para reaprender a língua munduruku e os significados que esta tarefa têm adquirido para os indígenas.

Ao longo do demorado processo de reconhecimento da comunidade de Taquara, que já dura 21 anos, a educação escolar indígena foi uma das principais, senão a principal conquista do grupo. Como resultado da primeira etapa de reconhecimento, em 2003, as salas de aulas que funcionavam na comunidade como anexo da escola Santa Filomena, localizada na comunidade vizinha de Prainha, deram lugar à escola indígena Laurelino Floriano Cruz, vinculada à Rede Escolar Municipal de Belterra. Inicialmente dotada apenas de Ensino Infantil e Ensino Fundamental I e II, a partir de 2011 ela passou a incluir o Ensino Médio (modular indígena), fruto de parceria com a Secretaria de Educação do Estado do Pará. Mas, tão importante quanto a implantação do ensino formal, têm sido a abertura da escola para uma dimensão diferenciada indígena, por meio da qual a escola tem assumido o importante papel de aparelho cultural dedicado à valorização e ao "resgate" de tradições.

Um marcador importante deste processo foi a inclusão da "Festa da Mani" entre as atividades da escola, destinada à comemoração da colheita da mandioca e à produção da farinha, na qual realizam-se rituais, danças, mas também assembleias. Foi em uma dessas assembleias, realizada em 2007, que teve lugar o debate público que levou à proposta de criação de uma disciplina voltada ao ensino da "Língua munduruku". Como resultado dessa discussão, em 2009 a escola indígena Laurelino Floriano Cruz recebeu o primeiro professor de munduruku (SILVA, 2013, p. 100).

Apesar de falarem o português, as lideranças de Taquara afirmam que esta não é sua língua "originária", mas uma língua imposta ou emprestada, que não lhes pertence. Por outro lado, a comunidade também não aderiu às primeiras iniciativas de revitalização da "língua indígena" na região, que se deram em torno do Nheengatú, língua geral com a qual muitos ainda mantinham laços memoriais. $O$ fato de sua afirmação étnica ter sido viabilizada pela reativação da memória de laços genealógicos com personagens munduruku localizados no tempo da fundação da comunidade, levou-os a conceber esta 
como sua língua "materna" - transformando, mas de forma coerente com o contexto local, o sentido comum atribuído à expressão. Segundo o cacique Francisco de Assis, que, ao lado do tuxaua Leonardo Pereira, lutou pelo ensino da língua munduruku na escola da aldeia:

\begin{abstract}
A importância da língua materna é porque... é o que... vamos supor, você tem um título [de eleitor], vai votar, mas aí eles pedem um [documento de] identidade, onde comprova... E a língua materna do índio [é com o que] ele comprova sua identidade, quer dizer, que mostra o que você é... Então, se você é munduruku você tem que dizer que você é, mas também mostrar que você fala a própria língua materna, [tem que] conhecer né? [...] Então, se eu dizer que eu sou, eu provo, [...] porque eu falo a minha própria língua, né? (Cacique Francisco de Assis).
\end{abstract}

Os munduruku de Taquara colocam-se, portanto, em uma situação linguística complexa, ao conceberem como parte de sua identidade uma língua que já não faz parte do seu cotidiano. O "resgate" da "língua materna" realiza-se, na prática, como o aprendizado de uma língua desconhecida, que pode ser lido como a busca pelo autoajuste às exigências da sociedade majoritária, diante dos estereótipos sobre o que é ser indígena. Oliveira e Pinto (2011) lembram que a língua foi tomada como um importante elemento definidor da identidade indígena pela sociedade não indígena, ao mesmo tempo em que a violência colonial operou no processo de destruição das sociedades indígenas justamente por meio dos processos de imposição de outras línguas. Entram também na complexa discussão acerca da autodesvalorização da diversidade linguística, expressa nos falares locais, da subordinação do oral ao escrito, típico da lógica educacional, da subordinação da razão comunicativa à razão técnica, que acompanha o recurso aos linguistas etc. (OLIVEIRA, 2006)

Mas o problema não se restringe à subordinação aos estereótipos da sociedade dominante. Por um lado, os próprios munduruku do alto rio Tapajós (uma população numericamente expressiva, concentrada nos municípios de Itaituba e Jacareacanga Estado do Pará), também expressavam desconfiança diante do processo de etnogênese da comunidade Taquara. Nas palavras do vice-cacique:

... até nossos parentes lá do alto, devido [nós] não falar mais a língua materna original... eles não queriam liberar professores pra vim pra cá [...], na mente deles que eles [os professores que vinham ensinar a língua munduruku] vinham de lá ensinar a língua materna que eles sabem, a cultura deles pra um povo que não é realmente munduruku. [...] Aí a gente começou a pressionar, que a gente era. Participamos de várias 
reuniões com os munduruku mesmo de lá do Alto, né? [...] Tivemos essa vitória assim de mostrar que realmente nós somos munduruku, só que infelizmente nós perdemos a nossa língua, nossa cultura. Então, só dentro desses doze anos, onze anos, que nós estamos de resgate da cultura, da língua materna. Para nós é uma vitória muito grande, nós ter conquistado isso, essa vitória de reconquistar e reconhecer a nossa língua. Que hoje tem alunos, até comunitários também, adultos que valoriza muito essa cultura, essa língua, né?

Por outro lado, o resgate-aprendizado do munduruku em Taquara foi viabilizado pelo o intercâmbio dos professores da aldeia com os próprios "parentes" munduruku do Médio e Alto Tapajós. A presença dos munduruku falantes da língua na condição de alunos da Universidade Federal do Pará localizada em Santarém, que ingressaram na universidade através do processo seletivo especial para indígenas, favoreceu a proximidade com a língua e a vinda de instrutores indígenas. Essa aliança não só possibilitou a revitalização da língua nas aldeias do Baixo Tapajós, como consolidou uma rede de alianças políticas entre o povo munduruku.

Assim, os habitantes de Taquara tiveram que provar aos parentes do Alto Tapajós que eram munduruku para conseguirem apoio na retomada da língua, em parte porque a retomada da língua é vista como fundamental para provar aos brancos que são munduruku, e em parte como forma de ativar o "parentesco" com outros coletivos munduruku.

O tema do "resgate" não se esgota, portanto, na dimensão de "prova" ou "adequação" impostas pelo processo de reconhecimento - que se desenvolve no plano da justificação na esfera pública. Ele opera também e fundamentalmente como parte do que foi chamado de processo de identificação, isto é, como elaboração subjetiva (individual e coletiva) do pertencimento identitário moralmente motivado (Arruti, 2006 p. 201), o que na linguagem local é traduzido na expressão sintética "se assumir" como indígena. O processo de identificação implicou em um trabalho social de reinvestimento de significados sobre a língua local, rompendo com o silêncio a que ela havia sido relegada, por motivos de sobrevivência. A senhora Joelma (neta de seu Laurelino), por exemplo, conta que sua vontade de aprender a "língua original" dos mais velhos está relacionada ao seu valor não só simbólico como afetivo: reestabelecer contato com sua ancestralidade, saber mais sobre sua origem. Aprender a língua para os mais velhos é se reconectar com uma memória fragilizada pelas censuras coloniais, acessar novamente o passado de forma distinta, tendo em vista a construção de um novo presente. A questão da lín- 
gua pode ser relacionada, portanto, à busca de uma linguagem por meio da qual possam se desfazer das relações de desrespeito para poderem se re-imaginar a partir de outros parâmetros.

No Planalto, como já adiantamos, a luta pelo reconhecimento territorial veio acompanhada pela imediata demanda por outros direitos, como a implantação de serviços de saúde e de educação diferenciadas indígenas. No campo da saúde os avanços não foram significativos, mas o campo da educação produziu mudanças importantes, com a implantação de escolas indígenas em todas as aldeias e a introdução das disciplinas de notório saber e língua munduruku, em conformidade com a demanda da própria organização indígena. Isso tornou a escola um espaço de afirmação étnica por excelência, e o ensino e aprendizado da língua um símbolo de conquista e demarcação cultural.

A introdução da língua indígena por meio da escola nas aldeias do Planalto é recente. Entretanto, há em vários depoimentos dos indígenas trazendo lembranças de algum ancestral que "falava língua de índio", atestando e reafirmando que toda aquela área era ocupada por indígenas desde muito tempo. Ao debater sobre o ensino da língua, os indígenas do Planalto atribuem valor ao seu aprendizado por ser um saber novo que pertence somente a eles e atribuem uma grande importância ao fato de que ser falante de uma língua indígena os torna diferente dos seus opositores. Assim, embora no caso do Planalto o tema da língua não tenha ainda o mesmo desenvolvimento vislumbrado na aldeia de Taquara, um episódio em especial é sempre lembrado pelas lideranças indígenas para balizar a importância da escola no seu processo de afirmação étnica e demostrar as constantes situações de desrespeito que enfrentam. O caso ocorreu em 2015, quando a esposa de um produtor de soja se matriculou no ensino médio noturno da escola indígena. O ensino modular foi, como dissemos, uma das conquistas do reconhecimento de Açaizal como comunidade indígena, desencadeado justamente em resposta ao avanço da soja. E uma das suas características, dentro da política de educação indígena do município de Santarém, é contar com uma grade curricular que inclui as disciplinas de Língua munduruku e de Notório Saber. No entanto, estendendo ao plano da escola a postura de desrespeito já reclamada no plano territorial, a esposa do sojeiro e uma amiga queriam se matricular sem cursar as disciplinas indígenas. Conforme relato de moradores e professores do Açaizal, elas "diziam que a escola não era indígena e que lá 
naquela comunidade ninguém era índio". Depois de alguns enfrentamentos diretos com os responsáveis pela escola, as duas mulheres procuraram o Ministério Público Estadual para reclamar serem obrigadas a cursar as disciplinas "dos indígenas".

No termo de declaração prestado à Promotoria de Justiça de Santarém (Ficha de atendimento Ministerial $n^{\circ}$. 084/2015-Mp/8aPJ) as duas requerentes relataram que após irem ao MPE apresentarem sua solicitação de esclarecimento, houve no mês de abril daquele mesmo ano uma reunião organizada pela diretora da escola para tratar sobre $o$ assunto. Estavam presentes na ocasião, além delas, os pais e responsáveis de alunos da escola, os professores e a responsável pela coordenação de educação indígena da Secretaria Municipal de Educação (Semed). Segundo relato das próprias mulheres, nesta reunião elas teriam sido difamadas tanto pela funcionária da escola quanto pela funcionária da Semed, que teriam dito que elas tinham "menos valor do que os indígenas" e que ambas deviam cursar as disciplinas ou buscar outra escola. Após este depoimento, o Ministério Público oficiou a Secretaria Municipal de Educação (Ofício nº. 244/2015$\mathrm{MP} / 8 \mathrm{aPJ}$ ) questionando-a sobre a obrigatoriedade ou não das mencionadas disciplinas, ao que a secretaria de educação respondeu (Ofício no. 175/2015- GAB-SEMED) que as disciplinas são uma demanda dos indígenas e que visam garantir, com o apoio da Secretaria Municipal de Educação, "o cultivo do saber diferenciado", mas elas não reprovam os alunos. O MPE manda então um ofício para a diretora da escola do Açaizal relatando a resposta da Secretaria de Educação, expressando seu respeito ao direito a uma educação diferenciada, porém solicitando que "os alunos que não se enquadrem como indígenas [não estejam] sujeitos à reprovação, assegurando a todos igualdade de tratamento e de oportunidade de direitos". Posteriormente, a direção da escola se manifesta acatando a orientação do MPE, mas, mesmo tendo conseguido o que queriam, as duas alunas não-indígenas não retornam à escola. Para as lideranças indígenas no Açaizal, tornava-se claro que a intenção das mulheres citadas era apenas "desmerecer" a luta indígena e, por isso, sua atitude era temerária, uma vez que poderia abrir caminho para que a escola deixasse de ser considerada indígena. Para além da obrigatoriedade de todos os alunos cursarem ou não as disciplinas voltadas para cultura indígena, o que estava em jogo na disputa em torno da escola era a disputa em torno do reconhecimento da legitimidade de um processo de recuperação cultural e linguística que compõem o 
processo de afirmação étnica.

Assim, o fato das políticas de resgate de língua indígena dentro das aldeias serem objeto de controvérsias entre indígenas não indígenas é a própria evidência de sua importância no processo de afirmação da identidade indígena e, consequentemente, da legitimidade do pleito territorial. A escola e, por meio dela, a língua, operaram como um expediente de territorialização dos munduruku do Planalto, que não se esgota neste evento específico. Tais controvérsias são um dos estímulos ao uso frequente da língua indígena nas performances políticas desses grupos nos momentos de embate público, projetando a sua afirmação identitária sobre diversos territórios semióticos, tanto quanto ao argumento de que a escola deve servir às finalidades definidas pelo próprio grupo para o seu território em sentido estrito.

\section{Considerações finais}

Nas breves descrições acima, buscamos evidenciar como a escola converteu-se em uma instituição estratégica para a organização social e cultural dos munduruku de Takuarra e Planalto. Neste processo de afirmação e formação, a língua indígena vem ganhando cada vez mais notoriedade, de forma que seu aprendizado e uso transitem entre diferentes significados, que vão da complexa relação entre enfrentamento e adequação à ideologia que nega suas identidades, até os expedientes de territorialização.

Este processo está repleto de contradições e armadilhas, como as montadas em torno das noções de estereótipo e autenticidade. Neste sentido é interessante colocar tais situações em comunicação (e, talvez, em comparação) com as experiências e dilemas vividos pelos povos indígenas do Nordeste. A reflexão de Laranjeiras Sampaio (2003) sobre os dilemas e contradições implicadas na ideia de "resgate cultural" são interessantes justamente neste sentido. Ao analisar as iniciativas de educação escolar indígena diferenciada desenvolvidas nos estados do Nordeste e em Minas Gerais, o autor aponta como a ideia de "resgate cultural" ao mesmo tempo em que afirma a identidade indígena, acaba fazendo isso segundo os padrões impostos pelo senso comum, que não coincidem com os modos de ser dessas populações hoje. O objetivo do "resgate" acaba por operar, na prática, como uma ação de reforma desses grupos, funcionando como uma tentativa de anular simbolicamente a história colonial, mais do que de compreendê- 
la e transformá-la. O "resgate" implicaria, enfim, em um "um procedimento pelo qual se poderia, ao menos em parte, devolver às sociedades indígenas a sua essência perdida e, no limite, fazê-las retornar ou reviver o seu estado original de encantamento e de verdadeira diversidade."

Tal "estado original" seria, porém, muito pouco original, na medida em que, por meio dessa ideia, tais grupos estariam em grande medida reproduzindo as concepções ideológicas da sociedade dominante sobre eles mesmos. Estaríamos no terreno do que Bourdieu (1977) designou como "classe objeto", ou seja, este tipo de classe social incessantemente convidada a tomar sobre si própria o ponto de vista dos outros. Desta forma, a ideia de uma educação diferenciada e específica, mobilizada na direção da busca pela autenticidade, cairia na armadilha dos estereótipos sobre o que deve ser o índio, realizando exatamente o oposto do que era a sua motivação inicial.

Tais críticas, realizadas, digamos, "de dentro", por um antropólogo engajado em diversos processos de formação de professores indígenas do Nordeste, apontam tanto para as armadilhas quanto para as oportunidades abertas neste jogo espelhos dos processos de afirmação e reconhecimento étnico. Como o autor chama atenção, foi também sob o desejo de realizar tais "resgates" que os professores indígenas tomaram conhecimento dos documentos históricos que davam acesso aos vocabulários das línguas dos seus supostos antepassados, às descrições sobre seus costumes, à sua iconografia etc. Com isso, o interesse inicial, voltado aos traços de cultura presentes naqueles documentos, converteu-se aos poucos no desejo de entender melhor os próprios documentos e processos históricos que em que eles foram produzidos, assim como os processos históricos, políticos e sociais que estiveram na base de tais "perdas". Tal movimento, segundo o testemunho de Laranjeiras Sampaio (2003), permitiu que a ideia de "resgate", eventualmente, pudesse ganhar um conteúdo mais crítico, capaz de objetivar a si mesma.

A situação dos munduruku do Baixo Tapajós, na sua luta pela escola e, dentro dela, pelo resgate da língua, está diante de riscos e oportunidades semelhantes aos descritos com relação aos povos indígenas do Nordeste. Enquanto a busca do resgate se mantem no plano do reconhecimento público, isso os vincula à reprodução de um modelo de indianidade imposto pela ideologia dominante (midiática, estatal, de mercado). 
Entretanto, tais resgates geram dinâmicas internas mais complexas, elas vão também construindo novas realidades e significados.

Ainda sem perder se caráter de imposição o ato de aprender e falar a língua Munduruku nestes dois territórios deixam evidente seu papel como elemento de resistência a negação da identidade indígena, da superação do preconceito, de argumento de união para a mobilização coletiva, bem como de elemento de distinção cultural e política dos coletivos tão necessários a estes povos. A própria língua indígena é defendida por estes sujeitos mais como marca e símbolo da luta do que como argumento de autenticidade.

Ainda que de forma ainda muito preliminar, a aproximação que realizamos neste texto entre língua e território busca apontar nesta direção, na medida em que o tema do "resgate"não se aplica apena à língua, mas também a outros campos nos quais operam os efeitos decorrentes dos dispositivos classificatórios com origem no Estado (Bourdieu, 2014). Tais classes de identificação estatais são também modelos imagéticos, que operam modelações sociais, ao imporem aos coletivos sociais padrões previamente catalogados. A noção de territorialização (OLIVEIRA, 1998) pode ser entendida também neste sentido (ARRUTI, 2006), já que a ideia de "território coletivo"também depende de um processo de tradução e adequação dos modos locais de gestão do espaço e da relação com a natureza, mediado pelo engajamento das comunidades nos processos (políticos, pedagógicos, simbólicos, organizativos) de luta pelo reconhecimento.

\section{Referências}

ARRUTI, José Maurício Andion. A Emergência dos Remanescentes. Mana. Out. 1997, vol. 3, n², p. 7-38. Disponível em: http://dx.doi.org/10.1590/S010493131997000200001 .. Acesso em 22 de agosto de 2018.

. "Etnicidade". In: Dicionário Crítico das ciências sociais dos países de fala oficial portuguesa / Org.: Lívio Sansone e Claudio Furtado. Salvador: EdUFBA / ABA ( $p$. 199-214), 2014.

BARTOLOMÉ, Miguel Alberto. As etnogêneses: velhos atores e novos papéis no cenário cultural e político. Mana. Rio de Janeiro, v. 12, n. 1, 2006. Disponível em: Acesso em Acesso em 22 de agosto de 2018.

BARTH, Fredrik. Grupos Étnicos e suas Fronteiras. In: POUTIGNAT-Phillipe; STREIFFFERNENT, Jocelyne. Teorias da etnicidade. Tradução de Elcio Fernandes. São Paulo: Editora da UNESP, 1998.

BOURDIEU, Pierre. "Une classe objet", Actes de la recherche en sciences sociales, 
1977, n. ${ }^{\circ}$ 17-18: $2-5$.

BOURDIEU, Pierre, Sobre o Estado. São Paulo: Companhia das Letras, 2014.

CAJIGAS-ROTUNDO, Juan Camilo. La biocolonialidad del poder: Amazonia, Biodversidad y Ecocapitalismo. In: CASTRO-GÓMEZ, Santiago; GROSFOGUEL, Ramón. (Ed.). El giro decolonial: reflexiones para una diversidad epistémica más allá del capitalismo global. Bogotá: Siglo del Hombre Editores, 2007. p. 169-193.

COSTA, Solange M. Gayoso (et al). Mapeamento social dos povos e comunidades tradicionais do rio Tapajós: povo munduruku e a luta pelo reconhecimento do território, Manaus: UEA-Edições, 2015 (Brochura).CUNHA, Manuela Carneiro da. Etnicidade: da cultura residual mas irredutível. In. Cultura com aspas e outros ensaios. São Paulo, Cosac Naify, 2009 [1979].

FONSECA, Wilde Dias da. Santarém, momentos históricos. 6 ed. Santarém: ICBS, 2015.

IORIS, Edviges Marta. Identidades negadas, identidades construídas: processos identitários e conflitos territoriais na Amazônia. In: ILHA - Revista de Antropologia. Florianópolis: UFSC, 2013. V.11, n.2, p.220-264. Disponível em https:// periodicos.ufsc.br/index.php/ilha/article/view/21758034.2009v11n1-2p219. Acessado em 05/05/2014.

IORIS, Edviges Marta. Uma floresta de disputas: conflitos sobre espaços, recursos e identidades sociais na Amazônia. Florianópolis: Editora da UFSC, 2014.

HONNETH, Axel. Luta por reconhecimento: a gramática moral dos conflitos sociais (Trad. Luiz Repa). São Paulo: Ed. 34, 2003.

MELIÁ, Bartolomeu. Bilinguismo e escrita. In: D‘ANGELIS, Wilmar; VEIGA, Juracilda. (Orgs). Leitura e escrita em escolas indígenas: encontro de educação indígenas no $10^{\circ}$ COLE 1995. Campinas, SP: ALB: Mercado de Letras, 1997.

OLIVEIRA, Gilvan Müller de. O que quer a Linguística e o que se quer da Linguística: A delicada questão da assessoria linguística ao Movimento Indígena. In: Formação de professores indígenas : repensando trajetórias / Organização Luís Donisete Benzi Grupioni. - Brasília : Ministério da Educação, Secretaria de Educação Continuada, Alfabetização e Diversidade, 2006, p. 175-.

OLIVEIRA, Elismênia Aparecida; PINTO, Joana Plaza. Linguajamentos e contrahegemonias epistêmicas sobre linguagem em produções escritas indígenas. In: Linguagem em (Dis)curso. v. 11, n.2, mai/ago, 2011, p. 311-35.

PACHECO DE OLIVEIRA, João (org.). A Viagem da volta: etnicidade, política e reelaboração cultural no Nordeste indígena. Rio de Janeiro: Contra Capa, $1999^{\text {a }}$

REGO, Gilson de Jesus.; VIEIRA, Judith Costa; NASCIMENTO, Nádia N.S. Fialho. Oceypi Ekawen (História da Nossa Terra). Santarém: Comissão Pastoral da Terra. Santarém-Pará, 2016.

SANTOS, Paulo Rodrigues dos. Tupaiulândia, Santarém, Pará. I Vol. 2 ed. Belém (PA): GRAFISA, 1974.

SAMPAIO, José Augusto Laranjeiras. "O 'resgate cultural' como valor: reflexões an- 
tropológicas sobre a formação de professores indígenas" In: Formação de professores indígenas : repensando trajetórias / Organização Luís Donisete Benzi Grupioni. - Brasília : Ministério da Educação, Secretaria de Educação Continuada, Alfabetização e Diversidade, 2006, p. 165-174.

SILVA, Sâmela Ramos. A dimensão identitária da língua Munduruku. 2013. 133 f. Dissertação (Mestrado em Letras e Linguística). Faculdade de Letras, Universidade Federal de Goiás, Goiânia, 2013.

SILVA, Sâmela Ramos; VAZ FILHO, Florêncio Almeida. O Nheengatú no rio Tapajós: revitalização linguística e revitalização política. In: Anais...do II Congresso Internacional Línguas, Culturas e Literaturas em diálogo: identidades silenciadas. Brasília, 2018, no prelo.

SPIX, J.B.; MARTIUS, C.F.P. Viagem pelo Brasil: 1817-1820. v. 3. São Paulo: Edusp, 1981.

VAZ FILHO, Florêncio Almeida. A emergência étnica de povos indígena no baixo rio Tapajós, Amazônia. Tese (Doutorado em Ciências Sociais/Antropologia). PPGCSUniversidade Federal da Bahia, Salvador, 2010.

VAZ FILHO, Florêncio de Almeida. Pajés e encantados na re-etnicização do interior da Amazônia. In: Anais do Congresso Internacional em Ciências da Religião. Programa de Pós-graduação strict sensu em Ciências da Religião, Departamento de Filosofia e Teologia, Pontifícia Universidade Católica de Goiás. v.1. Goiânia: PUC Goiás, 2011(a), p. (183-203).

VAZ FILHO, Florêncio de Almeida. Povos Indígenas no Baixo Tapajós querem reconhecimento. In: RICARDO, Beto; RICARDO, Fany (Ed.). Povos Indígenas no Brasil. São Paulo: Instituto Socioambiental, 2011(b), p. (423-426). 